\title{
The Pursuit of the Beauty of Physical Exercise
}

\author{
Xiaodan Chen $^{1 *}$, Yiyi Chen ${ }^{2}$ \\ ${ }^{1}$ Wangxiang Primary School, Jianxi District, Luoyang 4710221, Henan, China \\ ${ }^{2}$ Physical Education College of Luoyang Normal University, Luoyang 471000, Henan, China \\ Email: xiaodanyzy@126.com
}

\begin{abstract}
Proceeding from the perspective of aesthetics, this paper mainly adopt the Chinese traditional aesthetic thought with the reference to western mainstream aesthetic theory and focuses on the analysis of the beauty of sports at the micro level. At the same time, the competitive sports, campus education and beauty embodied in the sports for all were recovered and explored and interpreted with the aim to enable more people to be clear of the charm of sports exercise and to improve the appreciation level of people on physical exercise, inspire more people to take part in sports exercise, promote the development of people's physical and mental health level, improve the quality of life of the people. The development of the theories and thoughts of sports aesthetics cannot be separated from the cultural consciousness and guidance of the scholars and workers in this field, and it is also the embodiment of the cultural confidence and cultural consciousness of the sports workers.
\end{abstract}

Keywords: sports, aesthetics, cultural consciousness

\section{Introduction}

As early as in ancient Greece times, the concept of ideological understanding of beauty was nurtured. However, as a specialized discipline, aesthetics appeared in the German Enlightenment Movement in the 18th century. At that time, Baumgarten, a German scholar who had been teaching in universities, published the first volume of Aesthetics in 1750. After that, aesthetics gradually existed as an independent science. Later, Baumgarten was known as the "Father of aesthetics", and his thoughts had an important impact on the German classical idealist aesthetician such as Kant and Hegel. In China, With the emergence of Taoism and Confucianism in the Spring and Autumn Period and the Warring States Period. The understanding of beauty has been further developed. It is easier for the Chinese public to understand and accept the beauty of sports by using Chinese aesthetic thoughts and theories. Moreover, the development of any kind of cultural thought cannot be separated from the cultural consciousness and cultural guidance of scholars in this field. Today's China is moving forward from a big country in sports to a powerful country in sports. As scholars and workers in the field of sports, we should build up our cultural confidence and strive for the development of sports culture and the promotion and popularization of sports activities, so that more and more people can enjoy the beauty and pleasant emotional experience of participating in sports.

\section{The understanding and analysis on aesthetic ideology by China and western countries}

\subsection{The understanding and analysis on aesthetic ideology by western countries}

The germination of western aesthetic thought can be traced back to the Pythagorean school in ancient Greece, which believed that the most basic element of everything was number and that beauty was harmony. Only when many things were contained in unity like music, could beautiful music be heard. When it comes to Socrates, beauty is not easily defined and it is ineffable, which is not to be explained by certain concept. Soon after that, Kant, the representative of German classical aesthetics, had a new understanding of beauty analysis. Kant divided beauty into free beauty (pure beauty), or only dependent beauty (dependent beauty). Similarly, Hegel divided beauty into natural beauty and artistic beauty, and he paid more attention to the significance and value of artistic beauty. And that beauty is the perceptual manifestation of the idea.

From the establishment of aesthetic as a discipline to the analysis by Kant and Hegel systematically on beauty, a series of changes are used to tell a truth to the world: Beauty exists in "the inherent beauty" and all we need is to discover and to truly feel and recognize it so as to make it happen of personal aesthetic experience, which indicates the importance of cultural consciousness. Therefore, from the perspective of the development of aesthetic thought, the existence of beauty and human's 
pursuit of beauty enrich the understanding and theory of beauty. Although beauty is not an entity, it can realize aesthetic experience through entity or object image and human's participation. Beauty is perceptual, but the existence of beauty is objective and real.

\subsection{The analysis on beauty by traditional Chinese aesthetic thought}

The concept of Ben Gua Tuan Ci in the Book of Changes puts it this way: "There are men and women in the world men signify power and women mean gentleness, and the combination of both forms the law of the universe, that is nature. Men and wome can be paired as wife and husband so as to established a familiy and the nation. Moreover, the nation and the world mean culture". It tells us that "The gentleness can enhance the vitality of power", which signifies the philosophical thought of "Yin and Yang". At the same time, Lao Tzu said in the second chapter of his Tao Te Ching: "People know what is beauty and then they will know what is ugly. If we all know what is good, then we will know what is bad. So the absence and presence, easiness and difficulty are mutually dependent. Length and shortness can be compared, superiority and inferiority draw advantages over each other." Laozi dialectically set beauty and ugliness in opposition, and understood beauty through "Tao". He believed that complying with the laws of nature would enable his individual body and mind to develop freely and fully, which coincides with the harmonious thought in the Book of Changes that "Yin and Yang is called Tao".

With the appearance of Confucius, he made a further study and interpretation of the Book of Changes. He combined beauty with "Benevolence" and embodied the moral cultivation of the integration of "culture" and "quality". Confucius said "As simpleness is more than cultural cultivation, one would be more like a countryside man, otherwise, one would be hypocritical. The proper combination of the two, one could be a true man." It can be seen that although Chinese and Western scholars have different understandings of beauty due to different cultural backgrounds, there are still similarities. Both of them are undoubtedly convinced of the existence of beauty, and can connect corresponding aesthetic thoughts through the "line" of "beauty". In the West, the idea that beauty is harmony has long been reflected in the Book of Changes, a harmonious thought of "the unity of man and nature".

\section{Pursuit of the beauty of sports}

\subsection{The beauty of natural objects in sports}

The so-called object image, in essence, is the quality of Qi, which is the Xiang of Qi, it has the characteristics of condensing and solidifying from non-material to material, also has the tendency of spreading and diverging from material to non-material. Thus, when people do sports, the physical images and the beauty of emotion in nature are shown and brought into their own emotional experience. At the same time, people in sports also create beauty and enjoy beauty, such as "Cheng Fei Jumping" movement in gymnastics, namely 180- straight forward somersault turn 540.

Before this movement, everyone was attracted by the external "Form and spirit" of the athletes, which is the expression of physical beauty in Chinese aesthetic thought. At the same time, the rise from "form and spirit" to the "Qi" of the beauty of natural images is the characteristic of static and beautiful. In action in the process, the external beauty of the "object" immediately to pull the aesthetic subject into a not the real world, let the aesthetic subject and aesthetic object fusion image into a set of beautiful thought, aesthetic subject to realize athletics gymnastics beauty brought by the shock and sublime, it is unable to realize in the non-sports world "the beauty of the natural object".

\subsection{The beauty of humanistic spirit in sports}

In the Chinese version of the hexagrams, it is said that "Humanity is the way to make the world". The so-called "humanity" refers to all kinds of "mixed" things in human society that are different from nature, including the whole material culture and spiritual culture, of which beauty is only one aspect, and it is different from nature. The "beauty" reflected in the humanities here coincides with the aesthetic thoughts of Confucius and Mencius, and the beauty of such humanistic spirit will be further interpreted in sports. For example, since ancient times in Chinese martial arts, there has been the concept of "stop at where it should and overcome people with virtue", which does not mean that both sides are "afraid" of being hurt, but reflects the thousands of years of traditional Chinese etiquette culture and the realm of noble personality cultivation. There is also a beautiful emotional experience of life in which heroes pity each other and bosom friends know each other.

When the competition begins, the "Qi" of the "body" rises to the inner spiritual world of the aesthete, and the aesthetic object and the spirit of the aesthetic subject are integrated, so as to experience the profound inner beauty of humanistic spirit conveyed by the seemingly simple and repetitive body movements. It is not the innate beauty of nature, but reflected by the value of beauty which is interlinked with "Tao" by individual inner personality cultivation and moral quality, and it is a kind of physical manifestation of the beauty of art "works". 


\subsection{The beauty of artistic "works" in sports}

The reason why art is different from religion and philosophy is that it uses perceptual form to express the most sublime things, so that it brings the most sublime things closer to the view of nature, closer to our feelings and emotions. Therefore, art works show the inner spiritual quality of the created thing through the explicit form of material, while human sports use human "material" to express various forms of movement through body movements, and bring different aesthetic feelings. Even the "self-re-creation" of the athletes, or "works by the God", which is hard to be surpassed by later generations.

Such as the technical movement in "Cheng Fei jump" of the gymnastics project can be called a perfect masterpiece: A perfect movement with Straight forward somersault 540, and the last jump is not only an intuitive "works" in the eyes of the aesthetic subject, but also the beauty of the inner humanistic spirit that a well-trained athlete wants to convey through the display of the natural "object", thus achieving a living artistic "work". The aesthetic subject and the aesthetic object are immersed in the world of sports together, feeling and experiencing the manifestation of the concept of beauty in the "world of sports", which is the perceptual experience of the beauty of life practice in sports.

\subsection{The beauty of life practice in sports}

When the beauty of life practice and human sports encounter, the "life practice" shows the beauty of the external "natural image", and at the same time, the aesthetic experience of the internal harmony of rationality and sensibility is conveyed. At the moment when the ball is in front of the door, the goalkeeper needs to be highly concentrated and reasonable cooperation between teammates is required, the striker's proper and rational judgment and observation for the route to go so is needed to make the best action and decision. Under the premise of not violating the rules of the game, the ball can be shot into the goal in a more concise and excellent way.

Such advanced practical and rational prediction of achievements is not only the victory of the competition, but also leads to the perceptual experience of the beauty of life practice, so that the viewers and athletes are integrated into an unrealistic "sports world", and experience this exciting and shocking sublime beauty. Another example is leisure and entertainment sports, even if there is no excitement and shock of the beauty brought by competitive sports, such sports brings more natural manifestations of beauty in life practice. This is a kind of sports closer to "life practice", a sport to realize self-worth. More importantly, it is the process of self-improvement of the individuals in personality and morality.

\subsection{The beauty of the development of sports}

Up to now, the development of Chinese and Western sports witnessed a history of thousands of years, and has undergone subtle changes with the change of the background of the times. However, there is always a constant "inherent thing" in it. It is not an entity, which will definitely not be defined by concepts, nor touched like concrete objects. However, it can be perceived and experienced in life practice with the help of nature, object and humanistic spirit. It is a symbol of human wisdom, and it is the objective perceptual manifestation of the beauty in the development course of sports.

In 2019, China Women's Volleyball Team fought hard and won the final Women's Volleyball World Cup championship, which once again demonstrated the beauty of the development process of the sport of "the spirit of women's volleyball". In the same way, the generation and development of sports, the re-continuity and improvement as well as development should undergo various changes over the times to show what we see it is now and behind the "women's volleyball team spirit" is the demonstration of the age of the hard work of those sports. This is the beauty of a noble development course, the most direct and true expression of the athletes' love for life and pursuit of sports, the embodiment of the value of life, and more importantly, the display and interpretation of the beauty of the development course of self-sport.

\section{Summary}

Sports is not only the integration of the beauty of the external natural images and the beauty of the art "works", but also the inner embodiment of the beauty of the humanistic spirit, and through the mutual integration of life practice, a visual feast of the beauty in the development of sports. They coexist harmoniously and coexist with each other, which can convey the Chinese aesthetic thought of "The unity of man and nature". At the same time, the beauty always exists in the development process of sports. Their existence is the harmonious and unified embodiment of the beauty of natural images, the beauty of humanistic spirit and the beauty of artistic "works", and shows the beauty of unique development process although the contents of various sports, technical skills and sports concepts are different. 


\section{References}

[1] Hegel. Aesthetics (Volume 1). Beijing: The Commercial Press; 2015.

[2] Fu Xi, Zhou Wenwang. Famous Annotations Zhou Yi. Hefei: Huangshan Publishing House; 2012.

[3] Li Zehou, Liu Gangji. History of Chinese Aesthetics. Hefei: Anhui Literature and Art Publishing House; 1999.

[4] Liu Chengji. Philosophical Basis of Natural Beauty. Wuhan: Wuhan University Press; 2008.

[5] Li Zehou, Liu Gangji. History of Chinese Aesthetics. Hefei: Anhui Literature and Art Publishing House; 1999. 